\title{
Lack of Association Between Superoxide Dismutase Gene Polymorphism and Malignant Lymphoproliferative Disorders
}

\author{
Alireza Nakhaee, ${ }^{1,2}$ Mohammad Ali Mashhadi, ${ }^{3,4,{ }^{*}}$ Mohaddeseh Zademir, ${ }^{5}$ Zahra Sepehri, ${ }^{6}$ and Derek \\ Kennedy ${ }^{7}$ \\ ${ }^{1}$ Cellular and Molecular Research Center, Zahedan University of Medical Sciences, Zahedan, IR Iran \\ ${ }^{2}$ Department of Clinical Biochemistry, Zahedan University of Medical Sciences, Zahedan, IR Iran \\ ${ }^{3}$ Health Promotion Research Center, Zahedan University of Medical Sciences, Zahedan, IR Iran \\ ${ }^{4}$ Department of Internal Medicine, Zahedan University of medical Sciences, Zahedan, IR Iran \\ ${ }^{5}$ Department of Radiology, Zahedan University of Medical Sciences, Zahedan, IR Iran \\ ${ }^{6}$ Department of Internal Medicine, Zabol University of Medical Sciences, Zabol, IR Iran \\ ${ }^{7}$ School of Natural Sciences and Eskitis Institute for Drug Discovery, Griffith University, Brisbane, Australia \\ "Corresponding author: Mohammad Ali Mashhadi, Health Promotion Research Center, Zahedan University of Medical Sciences, Zahedan, IR Iran. Tel: +98-5433295607, Fax: \\ +98-5433295607, E-mail: mamashhadi67@yahoo.com
}

Received 2016 March 13; Revised 2016 April 22; Accepted 2016 April 23.

\begin{abstract}
Background: Superoxide dismutase is one of the most important antioxidant enzymes that protect cells against destructive effects of superoxide anion.

Objectives: The aim of this study was to evaluate the association between the C47T polymorphism (rs4880) of the manganese superoxide dismutase (Mn-SOD) gene and the risk of malignant lymphoproliferative disorders (MLDs).

Patients and Methods: Manganese superoxide dismutase polymorphism was genotyped using polymerase chain reactionrestriction fragment length polymorphism (PCR-RFLP) in 103 patients with MLDs and 103 healthy control subjects.

Results: The frequencies of the CC, CT and TT genotypes were $29.1 \%, 51.5 \%$ and $19.4 \%$, respectively, in patients with MLDs and $24.3 \%$, $47.6 \%$ and $28.2 \%$, respectively, in the control group. There were no statistical differences in the genotype or allele frequency of rs 4880 between cases and controls.

Conclusions: According to the fact that Mn-SOD gene polymorphisms have been considered as a major risk factor in some malignancies, this single center study did not find any association between the rs4880 polymorphism of the manganese superoxide dismutase gene and risk of MLDs.
\end{abstract}

Keywords: Superoxide Dismutase, Polymorphism, Lymphoproliferative Disorders, PCR-RFLP

\section{Background}

Malignant lymphoproliferative disorders (MLDs) are a heterogeneous group of disorders that result from the clonal proliferation of B, T, and NK cells (1). Common lymphoproliferative disorders include: chronic lymphocytic leukemia (CLL), acute lymphoblastic leukemia (ALL), lymphomas and multiple myeloma (2). There are several inherited gene mutations that have been identified to cause MLDs. Researchers also claim that viral, genetic, environmental and immunological factors may be involved in the pathogenesis of MLDs (3-5).

Reactive oxygen species (ROSs) are formed as obligatory intermediates in a variety of enzyme reactions. Furthermore, white blood cells generate radicals and utilize them to kill invading pathogens (6). Cells exposed to abnormal environments such as hypoxia or hyperoxia generate abundant and often damaging reactive oxygen species (7). A number of drugs have oxidizing effects on cells and lead to production of oxygen radicals. Ionizing radiation is also known to generate oxygen radicals within biological systems $(7,8)$.

Reactive oxygen species, when generated in excess or inappropriately controlled, can be harmful to the cells (9). Direct toxic effects of oxygen radicals can damage macromolecules, including lipids, proteins and DNA. As a result of these toxic effects, cells may undergo changes leading to carcinogenesis (10).

Normally, ROS are neutralized by specific biochemical pathways within the host cells (11). These pathways can be affected by genetic background and mutations in genes encoding components of these pathways and have been implicated in the pathogenesis of some MLDs (12, 13). One such mechanism utilizes superoxide dismutases (SODs), which can catalyze the conversion of two superoxide anions into a molecule of hydrogen peroxide $\left(\mathrm{H}_{2} \mathrm{O}_{2}\right)$ and oxygen $\left(\mathrm{O}_{2}\right)$ and this constitutes the first line of de- 
fense against ROS. There are three SOD types in mammals; $\mathrm{Cu} / \mathrm{Zn}$ SOD (SOD1) is found in the cytosol as well as in many of the organelles of eukaryotic cells. There is also an extracellular Cu/Zn SOD (SOD3) that binds to the glycosaminoglycan of the extracellular matrix. The Mn-SOD (SOD2) is found in the matrix of mitochondria and detoxifies superoxide anions produced during electron transfer (14).

The Mn-SOD protein is coded by the nuclear genome. Its gene is located on the long arm of chromosome six and has five exons and four introns (15). Approximately three hundred and seventy (370) polymorphisms have been reported for the Mn-SOD gene (16). Two well-documented polymorphisms of the Mn-SOD gene include a substitution of $\mathrm{C}$ to $\mathrm{T}$, at nucleotide residue 339 , leading to a substitution of isoleucine by threonine at amino acid residue 58 of the protein. The second is a substitution of $\mathrm{T}$ to $\mathrm{C}$ at nucleotide 47 resulting in a change of the amino acid from valine to alanine at the 16 th residue of the signal sequence (Val16Ala). These two mutations are common worldwide $(17,18)$. The Val16Ala polymorphism in Mn-SOD is associated with increased risk of several types of cancer, namely gastric cancer (19), breast cancer (20), prostate cancer (21) and colorectal cancer (22). The effect of Mn-SOD polymorphisms as a risk factor in lymphoproliferative disorders remains unknown.

\section{Objectives}

The present study aimed to investigate the association of the Ala16Val polymorphism of Mn-SOD gene with the risk of lymphoproliferative disorders in a group of patients in the southeast of Iran.

\section{Patients and Methods}

\subsection{Patients and Controls}

In this single center case-control study we evaluated one hundred and three cases with lymphoproliferative malignancies (40 cases with lymphoma, 27 cases with acute lymphocytic leukemia (ALL), 25 cases with chronic lymphocytic leukemia (CLL) and 11 cases with multiple myeloma) with a mean age of $53.6 \pm 11.1$ years, who had been admitted to the department of hematology and oncology of AliIbn Abitaleb of Zahedan. The same numbers of unrelated healthy blood donors with a mean age of $55.1 \pm 10.6$ years, without any type of malignancies were selected as the control group. Diagnosis and the classification of malignancies were made by histological examination of biopsied material stained using the Hematoxylin-Eosin (HE) techniques. Inclusion criteria were being over 18 years of age, having lymphoproliferative malignancies. The patient exclusion criteria were having malignancies other than lymphoma or any immune disorder. The protocol was approved by the research ethics committee of the Zahedan medical sciences university and informed consents were obtained from all participants. Two milliliters of venous blood was collected in EDTA tubes from all patients and control subjects. Genomic DNA was extracted from peripheral blood leukocytes using DNA blood mini kits (QIAGEN science, Germantown, MD), according to the manufacturer's instructions. Extracted genomic DNA was stored at $-20^{\circ} \mathrm{C}$ until use.

\subsection{Genotyping of the SOD2 T/C Polymorphism (rs4880)}

Polymorphism was determined using a polymerase chain reaction-restriction fragment length polymorphism (PCR-RFLP) method. Initially, an amplicon of the SOD2 gene containing the $\mathrm{T} / \mathrm{C}$ polymorphism was amplified using the primers sod2F: ( $5^{\prime}$-CGG TGA CGT TCA GGT TGT TCA C- $3^{\prime}$ ) and sod2R: (5'- CAG CAC TAG CAG CAT GTT GAG C-3'). The primers were designed using the FastPCR software according to the reference sequences in the NCBI, and then BLASTed to test them in silica specificity. The PCR reaction was performed in a $25-\mu \mathrm{L}$ volume containing 20 pmoles of each primer, $0.2 \mathrm{mM}$ of each dNTP, $2.5 \mu \mathrm{L}$ of buffer and $0.5 \mathrm{U}$ of Taq DNA polymerase, with an initial denaturation at $94^{\circ} \mathrm{C}$ for five minutes, followed by 32 cycles of $45 \mathrm{sec}$ onds at $94^{\circ} \mathrm{C}, 45$ seconds at $61^{\circ} \mathrm{C}$ and 45 seconds at $72^{\circ} \mathrm{C}$ and finally 10 minutes at $72^{\circ} \mathrm{C}$. Following amplification, the 490-bp PCR product was digested overnight at $60^{\circ} \mathrm{C}$ in a total reaction volume of $25 \mu \mathrm{L}$ containing $2 \mathrm{U}$ of BsaWI restriction enzyme (New England Biolabs GmbH, Schwalbach, Germany). The resultant DNA fragments were analyzed and scored on an ethidium bromide stained agarose gel (2.5\%) and visualized on a UV transilluminator.

\subsection{Statistical Analysis}

Statistical analysis was performed with the SPSS software (version 18). Differences between the means of the continuous variables were evaluated by the Student's ttest. The chi-square test was used to compare the genotypes and alleles between controls and patients. Departure from Hardy-Weinberg equilibrium was tested among control and patient groups using chi-square $\left(\chi^{2}\right)$ tests. The associations between SOD genotypes and lymphoproliferative disorders were estimated as odds ratios (OR) and 95\% confidence intervals ( $95 \% \mathrm{CI}$ ) using logistic regression analysis. A P value of $<0.05$ was considered statistically significant. 


\section{Results}

A total of 206 individuals were included in this study (Table 1). There was no significant difference in age and gender distribution in patients and controls $(\mathrm{P}=0.43$ and $\mathrm{P}=0.89$, respectively).

Table 1. Demographical Parameters of Lymphoproliferative Patients and Control Groups

\begin{tabular}{lccc}
\hline Parameters & Patients & Controls & P \\
\hline Average age & $53.6 \pm 11.1$ & $55.1 \pm 10.6$ & 0.43 \\
Female, No. (\%) & $41(48.8)$ & $43(51.2)$ & 0.89 \\
Male, No. (\%) & $62(50.8)$ & $60(49.2)$ & 0.88 \\
\hline
\end{tabular}

The PCR amplicon (490 bp) following digestion yielded bands of 338 and 152 bp in TT homozygotes, and 490, 338 and $152 \mathrm{bp}$ in TC heterozygotes. The PCR product of CC homozygotes remained intact (Figure 1).

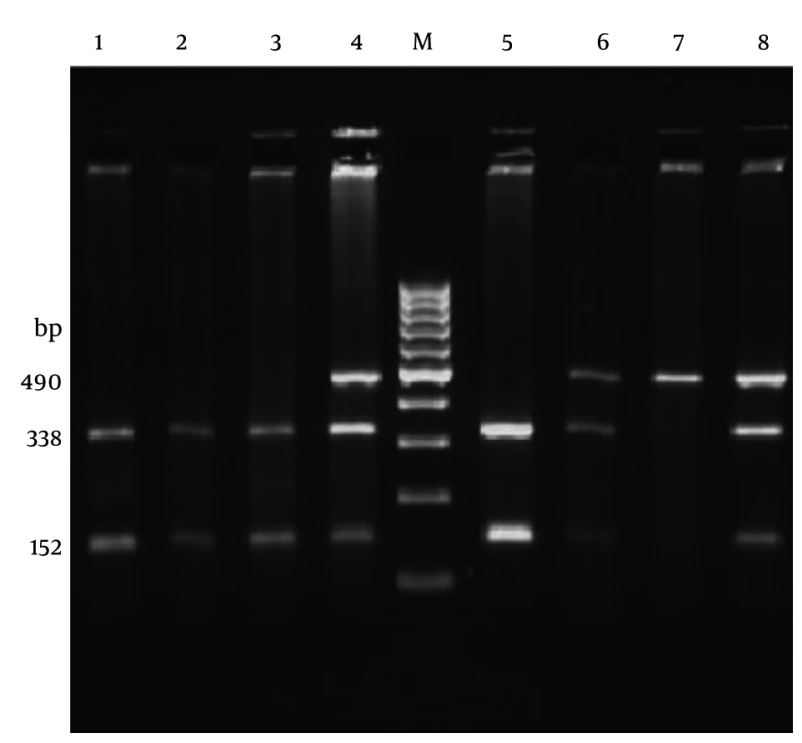

Figure 1. Polymerase chain reaction-restriction fragment length polymorphism analysis of the C47T polymorphism (Rs4880) in the SOD2 gene using $2.5 \%$ agarose gel electrophoresis. A single fragment of $490 \mathrm{bp}$ indicates a $\mathrm{C} / \mathrm{C}$ genotype, two fragments of 338 and $152 \mathrm{bp}$ indicates the $\mathrm{T} / \mathrm{T}$ genotype and the appearance of all three bands represents the heterozygous $\mathrm{C} / \mathrm{T}$ genotype. Lanes 1,2 and 3 show the T/T genotype; lanes 4, 6 and 8 show C/T genotypes and lane 7 shows C/C genotype. Lane $\mathrm{M}$ is a 100-bp DNA ladder.

As shown in Table 2, the TT genotype of the SOD2 gene was found in $28.15 \%$ of healthy controls and $19.41 \%$ of patients, and the CC genotype was observed in $24.27 \%$ of healthy controls and $29.13 \%$ of patients. The prevalence of CT genotype in healthy controls and patients were $47.57 \%$ and $51.45 \%$, respectively. There was no significant differ- ence in the frequency of genotypes between patients and controls $(\mathrm{P}>0.05)$.

Using logistic regression analysis, there was no association between genotype frequency and proliferative disorders (OR $=0.637,95 \% \mathrm{CI} 0.32-1.27)$. Also, a lack of association was observed between allele frequencies and MLD $(\mathrm{OR}=0.76,95 \% \mathrm{CI}=0.52-1.12, \mathrm{P}=0.16)$ (Table 2). The distribution of SOD2 genotypes in healthy controls and patients were consistent with the Hardy-Weinberg equilibrium $\left(\chi^{2}=0.23, \mathrm{P}<0.05\right.$ and $\chi^{2}=0.16, \mathrm{P}<0.05$, respectively).

\section{Discussion}

We examined associations between polymorphisms in the gene encoding Mn-SOD and risk of malignant lymphoproliferative (MLDs) disorders in a case-control study. Our results demonstrate that the Mn-SOD Val16Ala polymorphism (rs4880) is not a risk factor for MLDs. The Mn-SOD is encoded by the nuclear genome and after translation in the cytoplasm it is transported into the mitochondria via an N-terminal mitochondrial targeting sequence containing 24 amino acids. The substitution of $\mathrm{T}$ to $\mathrm{C}$ (rs4880) changes a Val to Ala at the $16^{\text {th }}$ position of the mitochondrial targeting signal peptide and this can alter the secondary structure of the enzyme (23). As a result of this substitution, transportation of the Ala variant of the MnSOD protein into the mitochondria decreases and the mitochondrial enzymatic activity is reduced when compared to the Val variant (24). Superoxide dismutase has an important role in ROS detoxification, thus protecting the cell from damage and carcinogenicity, particularly among individuals with a higher level of oxidative stress or who are deprived of other anti-oxidative protection, such as low levels of antioxidant intake (25).

Free radicals of oxygen could damage the cell and change cell proliferation, cell division and programmed cell death. As a result of oxidative damage caused by reduced function or inappropriate targeting of SOD2, the activity of tumor suppressor genes can be decreased and oncogenes may be activated (19). One downstream effect of ROSs production in cells is intensified DNA damage. Agedependent increases in the level of damaged DNA have been commonly assessed through biomarkers such as the formation of 8-oxo-2'-deoxyguanosine (oxo8dG) (26) and it is thought that there is a correlation between ROSs production in cells and DNA damage. Although our findings do not support the role of SOD2 polymorphism in the etiology of MLDs, reduction in activity of this enzyme has been reported in patients with lymphoproliferative disorders (27).

Our study compared polymorphism of superoxide dismutase type 2 (SOD2) in a healthy population compared to 
Table 2. Genotype and Allele Frequencies of SOD2 C47T Polymorphism (Rs4880) in Patients With Lymphoproliferative Disorders and Healthy Controls

\begin{tabular}{|c|c|c|c|c|}
\hline Frequencies & Control, No. (\%) & Patient, No. (\%) & OR $(95 \% C I)$ & $\mathbf{P}$ \\
\hline \multicolumn{5}{|l|}{ Genotypes } \\
\hline TT & $29(28.15)$ & $20(19.41)$ & Ref & \\
\hline $\mathrm{CT}$ & $49(47.57)$ & $53(51.45)$ & $1.62(0.84-3.12)$ & 0.19 \\
\hline $\mathrm{CC}$ & $25(24.27)$ & $30(29.13)$ & $1.74(0.80-3.8)$ & 0.23 \\
\hline \multicolumn{5}{|l|}{ Alleles } \\
\hline $\mathrm{T}$ & $107(52)$ & $93(45.2)$ & Ref & \\
\hline $\mathrm{C}$ & $99(48)$ & $113(54.8)$ & $1.3(0.89-1.9)$ & 0.2 \\
\hline
\end{tabular}

patients with lymphoproliferative disorders and showed a lack of association between the polymorphism and any of the disease states. This research was the first study, which reported these results. However, several studies have been performed to explore the relationship between SOD polymorphisms and human cancers. For instance, Woodson et al. showed that the Val/Ala polymorphism in the SOD2 gene increased the risk of prostate cancer by approximately $70 \%$ (28). One meta-analysis evaluation of polymorphisms in SOD, in relation to the risk of prostate cancer, showed a significant increase in cancer formation without any apparent change in the aggressiveness of prostate cancer (18). Blein and co-workers in a cohort study reported that the rs4880 Val16Ala polymorphism within the SOD2 gene was associated with increased risk of malignant breast and prostate cancers (29). Therefore, it seems that the polymorphisms within the SOD gene can be considered as risk factors for prostate cancer. Additionally, increased risk of breast cancer in Chinese women with high stress life style and low antioxidant intake was also shown (30). The positive correlations between the polymorphisms and other kinds of cancers have been reported by previous researchers. For example, in recent studies on Chinese populations, the association between SOD2 polymorphisms and the risk of gastric cancer and its progression revealed a positive association $(19,31)$. In contrast with the mentioned studies, there are several reports, which failed to confirm any association between SOD polymorphisms with the onset of malignancies. For example, Sutton et al. demonstrated that this polymorphism decreased the risk of lung cancer (18). Lightfoot et al. also reported decreased incidence of non-Hodgkin's lymphoma in homozygotes for the SOD2 16Ala allele in the UK population (27). Additionally, studies on bladder cancer were unable to indicate a positive correlation between polymorphisms within SOD gene and the occurrence of this form of cancer $(32,33)$. According to the results presented by our study and other investigators, it may be concluded that the correlation be- tween SOD2 polymorphisms is dependent on the kinds of cancers, for example, prostate and breast cancers appear to a have positive correlation, while, bladder and hematological malignancies, like lymphoproliferative disorders, are not associated with the polymorphisms of SOD2. The limitation of this study was the small sample size, so it seems that more investigations on Val16Ala polymorphism in larger samples and even other polymorphisms of the SOD gene can improve our knowledge regarding the role of SOD polymorphisms and incidence of lymphoproliferative disorders.

\section{Acknowledgments}

The authors are grateful to all individuals who willingly participated in the study and donated their blood.

\section{Footnotes}

Authors' Contribution: Study concept and design, Alireza Nakhaee, Mohammad Ali Mashhadi and Mohaddeseh Zademir; sampling, Mohammad Ali Mashhadi and Mohaddeseh Zademir; technical and material support, Alireza Nakhaee; analysis and interpretation of data, Alireza Nakhaee and Mohaddeseh Zademir; drafting of the manuscript, Zahra Sepehri, Derek Kennedy; study supervision, Alireza Nakhaee and Mohammad Ali Mashhadi.

Conflict of Interest: The authors had no conflict of interest to declare.

Funding/Support: This work was financially supported by a dissertation grant (MD. thesis of MZ) from Zahedan University of Medical Sciences.

\section{References}

1. Subramaniam K, D'Rozario J, Pavli P. Lymphoma and other lymphoproliferative disorders in inflammatory bowel disease: a review.J Gas troenterol Hepatol. 2013;28(1):24-30. doi: 10.1111/jgh.12015. [PubMed: 23094824]. 
2. Garon JE. Principles of clinical laboratory utilization and consultation. Arch Pathol Lab Med. 2000;124(4):644. [PubMed: 10747333].

3. Carbone A, Gloghini A, Dotti G. EBV-associated lymphoproliferative disorders: classification and treatment. Oncologist. 2008;13(5):577-85. doi: 10.1634/theoncologist.2008-0036. [PubMed: 18515742].

4. Kristinsson SY, Koshiol J, Goldin LR, Bjorkholm M, Turesson I, Gridley G, et al. Genetics- and immune-related factors in the pathogenesis of lymphoplasmacytic lymphoma/ Waldenstrom's macroglobulinemia. Clin Lymphoma Myeloma. 2009;9(1):23-6. doi: 10.3816/CLM.2009.n.004. [PubMed:19362964].

5. Tanner SM, Austin JL, Leone G, Rush LJ, Plass C, Heinonen K, et al. BAALC, the human member of a novel mammalian neuroectoderm gene lineage, is implicated in hematopoiesis and acute leukemia. Proc Natl Acad Sci U S A. 2001;98(24):13901-6. doi: 10.1073/pnas.241525498. [PubMed: 11707601].

6. Halliwell B. Free radicals, reactive oxygen species and human disease: a critical evaluation with special reference to atherosclerosis. BrJ Exp Pathol. 1989;70(6):737-57. [PubMed: 2557883].

7. Devasagayam TP, Tilak JC, Boloor KK, Sane KS, Ghaskadbi SS, Lele RD. Free radicals and antioxidants in human health: current status and future prospects. J Assoc Physicians India. 2004;52:794-804. [PubMed: 15909857].

8. Deavall DG, Martin EA, Horner JM, Roberts R. Drug-induced oxidative stress and toxicity. J Toxicol. 2012;2012:645460. doi: 10.1155/2012/645460. [PubMed: 22919381].

9. Hancock JT, Desikan R, Neill SJ. Role of reactive oxygen species in cell signalling pathways. Biochem Soc Trans. 2001;29(Pt 2):345-50. [PubMed: 11356180].

10. Cooke MS, Evans MD, Dizdaroglu M, Lunec J. Oxidative DNA damage: mechanisms, mutation, and disease. FASEBJ. 2003;17(10):1195-214. doi: 10.1096/fj.02-0752rev. [PubMed: 12832285].

11. Frei B, Stocker R, Ames BN. Antioxidant defenses and lipid peroxidation in human blood plasma. Proc Natl Acad Sci USA. 1988;85(24):974852. [PubMed: 3200852].

12. Battisti V, Maders LD, Bagatini MD, Santos KF, Spanevello RM, Maldonado PA, et al. Measurement of oxidative stress and antioxidant status in acute lymphoblastic leukemia patients. Clin Biochem. 2008;41(78):511-8. doi: 10.1016/j.clinbiochem.2008.01.027. [PubMed: 18313403].

13. Phoonlapdacha P, Chongviriyaphan N, Pakakasama S, Kalpravidh RW, Suthutvoravut U. Antioxidant status and lipid peroxidation in pediatric patients with acute lymphoblastic leukemia. FASEB Journal. 2008;22(1_MeetingAbstracts):890.9.

14. Zelko IN, Mariani TJ, Folz RJ. Superoxide dismutase multigene family: a comparison of the CuZn-SOD (SOD1), Mn-SOD (SOD2), and EC-SOD (SOD3) gene structures, evolution, and expression. Free Radic Biol Med. 2002;33(3):337-49. [PubMed: 12126755].

15. Church SL, Grant JW, Meese EU, Trent JM. Sublocalization of the gene encoding manganese superoxide dismutase (MnSOD/SOD2) to $6 \mathrm{q} 25$ by fluorescence in situ hybridization and somatic cell hybrid mapping. Genomics. 1992;14(3):823-5. [PubMed: 1427917].

16. Yuzhalin AE, Kutikhin AG. Inherited variations in the SOD and GPX gene families and cancer risk. Free Radic Res. 2012;46(5):581-99. doi: 10.3109/10715762.2012.658515. [PubMed: 22257147].

17. Borgstahl GE, Parge HE, Hickey MJ, Johnson MJ, Boissinot M, Hallewell RA, et al. Human mitochondrial manganese superoxide dismutase polymorphic variant Ile58Thr reduces activity by destabilizing the tetrameric interface. Biochemistry. 1996;35(14):4287-97. doi: 10.1021/bi951892w. [PubMed: 8605177].

18. Sutton A, Khoury H, Prip-Buus C, Cepanec C, Pessayre D, Degoul F. The Ala16Val genetic dimorphism modulates the import of human manganese superoxide dismutase into rat liver mitochondria. Pharmacogenet Genomics. 2003;13(3):145-57.

19. Yi JF, Li YM, Liu T, He WT, Li X, Zhou WC, et al. Mn-SOD and CuZn-SOD polymorphisms and interactions with risk factors in gastric cancer. World J Gastroenterol. 2010;16(37):4738-46. [PubMed: 20872977].

20. Mitrunen K, Sillanpaa P, Kataja V, Eskelinen M, Kosma VM, Benhamou $\mathrm{S}$, et al. Association between manganese superoxide dismutase (MnSOD) gene polymorphism and breast cancer risk. Carcinogenesis. 2001;22(5):827-9. [PubMed: 11323405].

21. Mao C, Qiu LX, Zhan P, Xue K, Ding H, Du FB, et al. MnSOD Val16Ala polymorphism and prostate cancer susceptibility: a meta-analysis involving 8,962 subjects. J Cancer Res Clin Oncol. 2010;136(7):975-9. doi: 10.1007/s00432-009-0742-x. [PubMed: 20012093].

22. Arsova-Sarafinovska Z, Matevska N, Petrovski D, Banev S, Dzikova S, Georgiev V, et al. Manganese superoxide dismutase (MnSOD) genetic polymorphism is associated with risk of early-onset prostate cancer. Cell Biochem Funct. 2008;26(7):771-7. doi: 10.1002/cbf.1504. [PubMed: 18646267].

23. Rosenblum JS, Gilula NB, Lerner RA. On signal sequence polymorphisms and diseases of distribution. Proc Natl Acad Sci U S A. 1996;93(9):4471-3. [PubMed: 8633092].

24. Shimoda-Matsubayashi S, Matsumine H, Kobayashi T, NakagawaHattori Y, Shimizu Y, Mizuno Y. Structural dimorphism in the mitochondrial targeting sequence in the human manganese superoxide dismutase gene. A predictive evidence for conformational change to influence mitochondrial transport and a study of allelic association in Parkinson's disease. Biochem Biophys Res Commun. 1996;226(2):5615. doi: 10.1006/bbrc.1996.1394. [PubMed: 8806673].

25. Ambrosone CB, Freudenheim JL, Thompson PA, Bowman E, Vena JE, Marshall JR, et al. Manganese superoxide dismutase (MnSOD) genetic polymorphisms, dietary antioxidants, and risk of breast cancer. Cancer Res. 1999;59(3):602-6. [PubMed: 9973207].

26. Balaban RS, Nemoto S, Finkel T. Mitochondria, oxidants, and aging. Cell. 2005;120(4):483-95. doi:10.1016/j.cell.2005.02.001. [PubMed: 15734681].

27. Lightfoot TJ, Skibola CF, Smith AG, Forrest MS, Adamson PJ, Morgan GJ, et al. Polymorphisms in the oxidative stress genes, superoxide dismutase, glutathione peroxidase and catalase and risk of non-Hodgkin's lymphoma. Haematologica. 2006;91(9):1222-7. [PubMed: 16956821].

28. Woodson K, Tangrea JA, Lehman TA, Modali R, Taylor KM, Snyder K, et al. Manganese superoxide dismutase (MnSOD) polymorphism, $\alpha$ tocopherol supplementation and prostate cancer risk in the AlphaTocopherol, Beta-Carotene Cancer Prevention Study(Finland). Cancer Causes Control. 2003;14(6):513-8.

29. Blein S, Berndt S, Joshi AD, Campa D, Ziegler RG, Riboli E, et al. Factors associated with oxidative stress and cancer risk in the Breast and Prostate Cancer Cohort Consortium. Free Radic Res. 2014;48(3):380-6. doi: 10.3109/10715762.2013.875168. [PubMed: 24437375].

30. Cai Q, Shu XO, Wen W, Cheng JR, Dai Q, Gao YT, et al. Genetic polymorphism in the manganese superoxide dismutase gene, antioxidant intake, and breast cancer risk: results from the Shanghai Breast Cancer Study. Breast Cancer Res. 2004;6(6):R647-55. doi: 10.1186/bcr929. [PubMed: 15535847].

31. Xu Z, Zhu H, Luk JM, Wu D, Gu D, Gong W, et al. Clinical significance of SOD2 and GSTP1 gene polymorphisms in Chinese patients with gastric cancer. Cancer. 2012;118(22):5489-96. doi: 10.1002/cncr.27599. [PubMed: 22517484].

32. Cengiz M, Ozaydin A, Ozkilic AC, Dedekarginoglu G. The investigation of GSTT1, GSTM1 and SOD polymorphism in bladder cancer patients. Int Urol Nephrol. 2007;39(4):1043-8. doi: 10.1007/s11255-0079179-9. [PubMed: 17340208].

33. Crawford A, Fassett RG, Geraghty DP, Kunde DA, Ball MJ, Robertson IK, et al. Relationships between single nucleotide polymorphisms of antioxidant enzymes and disease. Gene. 2012;501(2):89-103. doi: 10.1016/j.gene.2012.04.011. [PubMed: 22525041]. 